\title{
CINCUENTA AÑOS DE HISTORIOGRAFÍA ODONTOLÓGICA ESPAÑOLA (1895-1945)
}

\author{
Javier Sanz \\ Facultad de Odontología, Universidad Complutense de Madrid.
}

\section{RESUMEN}

La primera gran etapa de la historiografía odontológica española tiene lugar en el período de 1895 a 1945. La principal labor en este área corresponde a José Martínez Sánchez siguiéndole, con gran diferencia, José María Martínez del Castrillo, Mariano Riva Fortuño, Ramón Pons y Juan de Otaola. Dos autores posteriores, Eduardo Ruiz Esquíu y Ramón Arqués Miarnau, aportan trabajos de mayor mérito pero siempre, al igual que sus predecesores, a enorme distancia de los coetáneos historiadores de la medicina española.

\section{SUMMARY}

The first great historiographic stage of the Spanish dentistry corresponds to the years 1895-

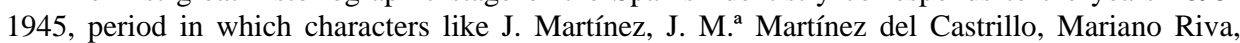
Ramón Pons and Juan of Otaola are analized, as the qualified elements in this odontologic stage.

$\mathrm{Al}$ contrario de lo que ha venido sucediendo en la historia de la medicina española, con orígenes en Villalba, Hernández Morejón o Chinchilla, entre los precursores, cuya obra abrió un camino historiográfico importante, carece la odontología de un acervo de similares características aunque esto no debe entenderse como una ausencia irreparable. En efecto, el análisis del pasado odontológico español ha contado con estudiosos que, de forma muy desigual, elaboraron repertorios que han servido de base a generaciones posteriores. De la misma forma, algunas aportaciones generales o particulares sobre el desarrollo de la profesión dental en España han constituido el material básico sobre el que se ha ido perfilando, y se perfilará, un mejor conocimiento de los orígenes y discurrir de la misma. Al análisis y reconstrucción de esta actividad emprendedora dedicamos el presente trabajo toda vez que la odontología ha constituido - $\mathrm{y}$ en la actualidad constituye- una profesión con entidad propia.

El período que aquí se desarrolla no es aleatorio sino que obedece a dos fechas documentadas de indudable significación. La más remota, 1895, corresponde al año en que aparece publicado, en forma de artículo, el primer índice de una serie de José Martínez Sánchez en busca de la recopilación bibliográfica de las obras de odontología 
escritas en castellano. La más próxima, 1945 -tan inmediata a la transformación de la odontología en una especialidad médica, la estomatología-, coincide con la edición de la Historia anecdótica de la odontología... de Arqués Miarnau y viene a cerrar la, a nuestro juicio, primera gran etapa de la historiografía odontológica española.

\section{LA OBRA DE JOSÉ MARTÍNEZ SÁNCHEZ}

Tratamiento muy especial merece la figura del dentista Martínez Sánchez iniciador y promotor de esta tarea en nuestro país.

\section{Nota biográfica}

Nacido en Méjico en $1847^{1}$, fue educado desde su niñez en España cursando el bachillerato y la medicina en Cádiz dedicándose desde los comienzos de su actuación profesional a la especialidad odontológica.

Los primeros años de la profesión los pasó en América siendo uno de los fundadores de la Sociedad Odontológica de La Habana y profesor de Mecánica en la Academia Dental de la misma.

En 1885 se estableció en Madrid -en 1887 estaba domiciliado en la calle Mayor, números 67 y 69-, donde formó a varios discípulos. En las revistas profesionales publicó numerosos trabajos científicos y fue el primer Presidente de Mesa de la Sociedad Odontológica Española, en cuyas sesiones participó largos años. En 1895 se da noticia ${ }^{2}$ de que regresaba a Madrid desde Cádiz -donde se había establecido hacía algunos meses- para abrir de nuevo su gabinete aunque poco más adelante se le cita «alejado hoy de la vida activa profesional.»

Falleció en Madrid el 24 de diciembre de 1917 siendo el decano de los dentistas españoles.

Martínez Sánchez publicó en Barcelona (1887) un gran libro titulado Arte del Dentista. Dividido en seis capítulos: anatomía y fisiología de la boca; patología y terapéutica; higiene, fórmulas que debe conocer el dentista; operaciones quirúrgicas que se practican en la boca; nociones de física y química aplicadas a los trabajos de taller; y prótesis y mecánica dental. El libro, de inspiración clara en la obra de Harris y otros autores de preferencia norteamericanos, se adaptaba al programa oficial de la

1 Anónimo (1917), «D. José Martínez Sánchez», La Odontología, 12, 678-679. Sobre todos estos autores, salvo Ruiz Esquíu y Arqués Miarnau -por razones puramente cronológicas-, nos hemos ocupado en nuestro Diccionario histórico de dentistas españoles, en prensa.

2 (1895), La Odontología, 4, 140-141. La reseña dice así: «El Dr. Martínez Sánchez, que durante muchos años estuvo establecido en Madrid, y que hace ya algunos meses se había instalado en Cádiz, traslada de nuevo su residencia a la Corte, donde muy en breve volverá a abrir su gabinete.» 
carrera de «Cirujano-Dentista» y puede considerarse uno de los mejores de su época, reuniendo prácticamente todo el saber necesario para el desempeño de la profesión. Ilustrado con cuatro láminas que recogen diferente instrumental odontológico y protésico, así como figuras anatómicas de la región, se culmina -ya se verá- con un apéndice sobre historia de la profesión dental en España.

En 1900 dio a la imprenta madrileña otro libro: Método para construir dentaduras en caoutchouc, en que a lo largo de sus 102 páginas pormenoriza sobre la técnica de fabricación de dentaduras con este material, y siete años después, en Madrid como el anterior, un tercero: Tratado completo y moderno sobre extracciones de dientes. Ambos, como es fácil deducir, tratan de los específicos temas de la profesión dental que sus títulos indican.

\section{Valor de su obra historiográfica}

Martínez Sánchez debe ser considerado el precursor de la «Historia de la odontología española» como queda dicho, pues a esta disciplina dedicó varios trabajos, siendo el primer estudioso español que se entregara, si no en exclusividad sí consagrando una buena parte de su obra científica, a estos asuntos.

En su notable tratado Arte del dentista, dedicó parte del contenido al abordaje de diferentes aspectos del pasado odontológico español. Así, el capítulo IV lleva por título: España, historia y estado actual de la profesión, siendo el del $\mathrm{V}$ y último: Reales órdenes relativas a la profesión dental. A continuación una Bibliografía dental española o catálogo de todas las obras impresas en castellano que tratan del arte del dentista, repertorio mejorado en publicaciones posteriores y, al final, un Apéndice al catálogo anterior. Con las obras que destinan especialmente una parte al arte del dentista. Era el primer libro odontológico donde se exponía la historia de nuestra profesión con rigor y método.

Como articulista, digna es de destacar la serie que, durante los años de 1895 a 1917 publicó en la revista La odontología sobre bibliografía dental española con los libros de la especialidad editados en castellano en los respectivos años anteriores, dando entrada a aquellos otros de los que no había tenido noticia previa y no se habían incluido en artículos precedentes. Aun con diferentes títulos, que en bien poco varían -por lo general bajo el epígrafe de Bibliografía dental española- y tienen el mismo propósito, la siguiente es la relación completa:

La Odontología, año de 1895, 150-157; 1901, 193-209 y 263-269; 1903, 670-673; 1905 , 170-175; 1906, 66-67; 1907, 545-549; 1908, 560-561; 1909, 373-376; 1910, 568-574; 1912, $26-311 ; 1914,24-31 ; 1915,97-105 ; 1916,36-43$ y $1917,63-64$. 
Con el material acumulado en varios de los referidos artículos, compendió en forma de monografía un catálogo que vio la luz, en 1911, bajo el título de: Índice para formar un catálogo razonado de todas las obras impresas en castellano que tratan sobre el Arte del Dentista ${ }^{3}$. Éste, constituye el primer repertorio documental al que los investigadores actuales recurrimos una y otra vez pues su contenido proporciona como ningún otro la información necesaria sobre las publicaciones odontológicas hispanas antiguas.

Pero no serían éstas las únicas aportaciones del dentista. En el V Congreso Dental Español (Valencia, 1907), había presentado una memoria en nombre de la «Comisión de Historia Dental» que, como bien reconocía el presidente de la misma, López Alonso, el trabajo de esta Comisión se debe exclusivamente al Sr. Martínez Sánchez ${ }^{4}$. Este informe, titulado Algunos datos estadísticos que pueden contribuir a una historia de la odontología en España ${ }^{5}$, recopilaba las noticias sobre colegios, sociedades y corporaciones odontológicas; legislación; prensa y libros, en tres diferenciados grupos. Todo, se entiende, referido a la profesión odontológica. El valor de esta memoria, aparte del rigor expositivo, radica en la vivencia del autor de muchos de los aconteceres que allí se narran. Bajo la misma presidencia, la comisión ${ }^{6}$ presentó en el VI Congreso Dental Español (Sevilla, 1909) un trabajo, de nuevo, de autoría exclusiva de Martínez Sánchez, aunque esta vez se trata solamente de una comunicación para salir del paso.

Otra vez un estudio presentado a congreso es publicado en forma de separata ${ }^{7}$. Nos referimos al titulado Monografía sobre la obra dental más antigua que trata del Arte dental, impresa en nuestro idioma y publicada en España y versa sobre los aspectos odontológicos incluidos en la Cirugía de Lanfranco. Con esta monografía se completa la producción científica del Martínez Sánchez historiador.

Mediando una notable distancia, podría decirse que abismal, un grupo de dentistas españoles posteriores siguieron el camino iniciado de forma tan brillante por Martínez Sánchez. No obstante, la magnitud de su obra valorada en su conjunto, queda muy por debajo de lo que cabría esperar tras el bagaje que aquél pusiera a su disposición. No son, por lo general, estudios monográficos de relieve, algunos no pasan de artículos que quizá en otros campos historiográficos, el de la medicina por ejemplo, no hubieran merecido siquiera la atención del historiador. Sin embargo, probable-

\footnotetext{
3 Este índice, con el mismo título, se presentó en forma de comunicación en el VI Congreso Dental Español celebrado en Madrid en 1911. Fue publicado en las actas del mismo al año siguiente (págs. 93-135).

4 (1908), La odontología, 4, 174

5 Ibidem, 174-184.

6 Formada además de López Alonso y Martínez Sánchez, por Edo Pastor, Calpe Soriano, Baca Sánchez y Espejel. La comunicación se publicó en el libro de actas del congreso (Sevilla, 1910), 160-165, bajo el anodino título de Informe de la comisión de Historia de la Odontología en España.

7 Se presentó al VII Congreso Dental Español, celebrado en Barcelona en 1914.
} 


\section{CINCUENTA AÑOS DE HISTORIOGRAFÍA ODONTOLÓGICA ESPAÑOLA (1895-1945)}

mente sea ésta la característica más significativa del periodo objeto de estudio, la pobreza tanto en la recopilación y actualización de fuentes para el estudio como la exposición histórica del pasado odontológico español.

También conviene dejar constancia de que no son sólo los aquí mencionados los historiadores únicos de la odontología en nuestro país. En fechas anteriores ya se había escrito algún artículo alusivo al tema, ocurriendo igualmente en tiempos ulteriores $^{8}$, pero tan sólo son «historiadores ocasionales» que se ocupan de temas generales y lo que nos trae aquí es tanto su dedicación más o menos constante como el desarrollo del tema español.

\section{UNA POBRE FORMACIÓN DOCENTE}

Ahora bien, ¿cuál era la formación académica de estos autores, si es que existía, en el área de la historia de la profesión?. En el «Colegio Español de Dentistas» fundado por D. Cayetano Triviño en $1873^{9}$, se tenía en cuenta desde sus orígenes la docencia histórica pues su reglamento establecía en el artículo 1 , apartado $10^{\circ}$ : «Como complemento de la esmerada instrucción del Dentista, se enseñará al alumno LA HISTORIA DE TODOS LOS RAMOS DE LA PROFESION...» ${ }^{10}$, teniendo como primeros profesores a D. José Precioso y López y D. Miguel Santa Cruz y Orugen (supernumerario) ${ }^{11}$. En el mismo centro, el célebre Antonio Rotondo ${ }^{12}$, titular de la asignatura «Operatoria Dental», incluía en su programa como primera lección: Historia del dentista español y descuido de los gobiernos sobre este punto ${ }^{13}$.

8 Nos referimos, por ejemplo, a LÓPEZ DE LA VEGA, J. (1873), «Desenvolvimiento histórico de la especialidad del cirujano dentista», Revista Odontológica, 225-241; TRIGUEROS SOMOZA, J. (1879), «Memoria histórico-profesional», Revista Odontológica, 264-279; CASASNOVAS, D. (1901), Antigüedad del arte dental y la ciencia odontológica, Palma de Mallorca, (folleto); LÓPEZ ALONSO, A. (1901), Bosquejo histórico sobre el arte dental, Madrid (folleto); CAROL, P. (1906), La profesión dental en España y factores que han contribuido a su cultura y desarrollo, Barcelona (folleto); PUIG SANCHÍs, F. (1933), «Historia de los remedios empleados para combatir la odontalgia», Trabajos de la Cátedra de Historia Crítica de la Medicina, 1, 123-141, y PESQuera Álvarez, A. (1935), «Historia de la odontología», Trabajos de la Cátedra de Historia Crítica de la Medicina, 6, 429-454.

9 Instalado en un primer momento en la madrileña calle de Capellanes, $\mathrm{n}^{\circ}$. 10, se inauguró oficialmente el 11 de enero de 1874.

10 (1873), Revista Odontológica, 12, 357-367. Anteriormente, en la instancia que Triviño dirigiera, con fecha 23 de junio de 1873, al Ministro de Fomento a fin de crear un colegio dental similar a los estadounidenses, proponía entre las asignaturas: «Y para el grado de Doctor, además de las antedichas, las de Jurisprudencia médica e Historia de todos los ramos de la profesión.»

11 Ibidem, 13, 412-416. Se da noticia del cuadro de profesores aprobado.

12 Cfr. SANZ, J. (1994), «Antonio Rotondo (1808-1879). Un dentista ilustrado», Revista Vasca de odontoestomatalogía, 1, 18-23.

13 (1873), Revista Odontológica, 112, 374. 
Establecido el título de «Cirujano-Dentista» por Real Decreto de 4 de junio de 1875, se publicó una Real Orden el 3 de marzo siguiente por la que quedaba aprobado el programa oficial de estos exámenes que incluía los siguientes temas: 47. Historia de la cirugía dental en España. 48. Consideraciones sobre su estado actual. 49. Historia de la cirugía dental y su estado actual en América. Inglaterra, Francia y demás países de Europa. Cuando cesara la actividad docente del centro de Triviño, agravada por la Real Orden de 1 de octubre de 1881 en que dejaba sin validez los títulos emitidos por el mismo, estos exámenes, realizados en el Hospital de San Carlos, se convertirían en una pantomima ${ }^{14}$.

A partir de la creación del título de «Odontólogo» -en cuya posesión estarían Ruiz Esquíu y Arqués Miarnau-, por Real Orden de 21 de marzo de 1901, esta parcela no iba a sufrir variaciones importantes pues tanto los primeros planes de estudio como la actualización de los mismos en 1910 no incluían lecciones relacionadas con la historia dental. Solamente la reforma de 1913 introducirá en la asignatura «Odontología primer curso, con su clínica» ${ }^{15}$ una lección aunque los subapartados de la misma constituían un cajón de sastre donde cabía todo menos historia: Contabilidad, código de deontología y legislación dental española. Conclusión: La formación histórica sobre su propio pasado, de una profesión con tan escasa tradición en los primeros momentos, se nos antoja nula; de ahí que el «amateurismo» y el autodidactismo fueran las únicas escuelas de los incipientes narradores de las etapas previas.

Lo anteriormente expuesto, no obstante, no debe ser motivo de extrañeza pues desde que se instaurara la profesión dental como una especialidad médica, la estomatología -en el año de 1944-, hasta la reciente creación de la licenciatura en odontología -en 1986- la situación no cambió un ápice toda vez que en tan largo período, y en el mejor de los casos, la historia de la odontología se resumía a dos únicas lecciones que formaban parte de un programa de otra asignatura.

\section{HISTORIADORES POSTERIORES}

El grupo de cultivadores de la historia, posteriores a Martínez Sánchez, a quienes venimos refiriéndonos, no constituyen un verdadero foro y no tienen en común sino

\footnotetext{
14 El examen, ante un tribunal compuesto no sólo por dentistas, tenía tres apartados: «construcción de piezas artificiales», «ejercicio práctico sobre un cadáver» y «ejercicio teórico» y acabó siendo una pantomima. Así protestaba Florestán Aguilar en su revista La Odontología, 252-253, tras los últimos exámenes de 1898: «Se presentaron 29, ¡los veintinueve fueron aprobados después de una repugnante comedia que los jueces del tribunal quieren llamar sarcásticamente examen, pero que cualquiera calificaría como escarnio de la enseñanza pública!

15 El programa fue proyectado por Aguilar y Landete.
} 
una misma afición en un tiempo que transcurre en el primer medio siglo actual. Son los siguientes:

José María Martínez del Castrillo (n. Tuy, 1868), fue discípulo de Higlands, Aguilar y Subirana, obteniendo el título de «Cirujano-Dentista» en 1897. Autor de varias obras odontológicas ${ }^{16}$, publicó como monografía -de 119 páginas- una Historia de la odontología (Madrid, 1916) tratándose de una comunicación presentada en el VIII Congreso Dental Español celebrado en Bilbao ese mismo año, advirtiendo en la introducción sobre las escasas pretensiones de la misma: «he conseguido dar a la publicidad una reseña o boceto de vulgarización en la que se atiende a la evolución de nuestra ciencia y las fases por que ha pasado...» Ello le daría pie, más adelante, a la publicación, en capítulos, de una Historia de la odontología de ámbito general y similares características, en la revista profesional Anuario Denta ${ }^{17}$. Por otra parte, en su Diccionario General de Odontología y Arte Dental ${ }^{18}$ (Madrid, 1904 y 1925) introdujo, en este sentido, varias reseñas biográficas de dentistas célebres, algunos españoles, si bien de forma poco rigurosa.

Otro «Cirujano-Dentista», el prolífico autor Mariano Riva Fortuño (n. Labuerda, 1849), que obtuvo aquel título académico en 1886 pasando a ejercer su profesión a Zaragoza, donde también editaría la revista El progreso dental entre los años de 1889 a 1900, publicó a los sesenta y ocho años un libro de 210 páginas titulado Historia crítica de la cirugía y arte dental (Desde Quirón hasta nuestros días), (Zaragoza, 1917), que no hemos tenido la fortuna de encontrar ${ }^{19}$ por lo que omitimos su análisis. De él se da cuenta en el número 15 de la revista España dental ${ }^{20}$ y levantó cierta polémica con Florestán Aguilar, como puede comprobarse en números posteriores.

Ramón Pons y Oms ${ }^{21}$ (Canet de Mar, 1868-Barcelona, 1935) acabó sus estudios de «Cirujano-Dentista» en 1894 pasando a París para ampliar conocimientos y regre-

16 Memorándum de Patología y Clínica dental (Madrid, 1899), Higiene práctica de la dentadura (Madrid, 1904) e Higiene de la boca para el soldado (Madrid, 1910).

17 Véanse los números correspondientes a 1922 -fecha de inicio de la publicación-, 1923, 1924 y 1925 bajo el rótulo «Historia de la odontología», curiosamente siempre entre las páginas 5 y 22 . En este número de 1925 (56) se aporta una reseña biográfica de Martínez del Castrillo en la que se cita un «Primer premio del Concurso celebrado en Madrid en 1900 para el mejor trabajo Antigüedad del Arte Dental». Ignoramos de qué concurso se trata.

18 Por esta obra se le concedió la Cruz de Plata del Mérito Militar con distintivo blanco, pensionada.

19 La biblioteca que Don Florestán Aguilar legara a la actual Facultad de Odontología, el mejor fondo bibliográfico odontológico del mundo, se encuentra embalada desde el curso 1991-92, por lo que durante todos estos años viene siendo imposible su consulta. Es más que seguro que en ella se encuentre esta obra, que no aparece en otras notables bibliotecas.

20 Cfr. nuestro trabajo Estudio histórico de la revista «España Dental». Comunicación presentada al X Congreso Nacional de Historia de la Medicina (Málaga, 1996).

21 Sobre este autor, consultar la necrológica escrita por MÁRQUEZ, E. (1936), «Don Ramón Pons y Oms», La Odontología, 1, 66-67. 
sando posteriormente a Barcelona. Editó una importante obra, Tratado de odontología, en 1910, 1914 y 1925, engrosando sus conocimientos en cada una de las sucesivas ediciones. Este texto se ceñía al programa oficial de Odontología, por lo que Florestán Aguilar le animó a transformar sus apuntes en un libro (así se advierte en el prólogo de la segunda edición). En la de 1925, en tres tomos, habla en el primero, capítulo segundo, de la historia de la odontología para desarrollar la Historia contemporánea española ${ }^{22}$, que tiene el valor de ser contada -en el período que media entre 1865 y la fecha de publicación de la obra ${ }^{23}$ - por un coetáneo riguroso, por lo que deja testimonio de instituciones, congresos, revistas, libros, etc. de su época, con menor riesgo de equivocación. No obstante, insistimos, la narración de la parte histórica española se reduce a cuatro escasas páginas ${ }^{24}$.

Además de algunos artículos sobre aspectos parciales de odontología internacional, no pueden ser despreciables en este páramo los relatos del también «CirujanoDentista» Juan de Otaola ${ }^{25}$ (Bilbao, 1864-Bilbao, 1944), que salieron en el Anuario dental de 1924, 1925 y 192626: «Efemérides decenales de odontología correspondientes al año 1924», haciendo lo propio, como queda dicho, los años siguientes. Tienen el valor, en su actualidad, de estar recogidos los datos con la intención de ser publicados por lo que, como sucede con Pons, admiten pocos errores.

De mayor relevancia es, sin duda, la obra de Eduardo Ruiz Esquíu (m. Madrid, 1969), que le convierte en el historiador odontológico español más importante de los años treinta y cuarenta, al recuperar con dignidad la línea de Martínez Sánchez. Tras varias publicacione ${ }^{27}$ en forma de artículo, editó monográficamente las dos siguientes en Madrid, en 1942, Aportaciones a la historia de la odontoestomatalogía y Bosquejo histórico de la odontología médico-legal. Un año después defendió su tesis doctoral cuyo título fue Ensayo histórico biobibliográfico sobre la odontología española hasta el siglo XIX, publicándola al año siguiente. Este trabajo se vio completado con la comunicación Repertorio biobibliográfico de las obras españolas de odonto-

\footnotetext{
22 Pons y OMs, R. (1925), Tratado de Odontología, Madrid, 3. a edición, 9-12.

23 Elige la primera fecha como la de la fundación de la primera sociedad dental española, refiriéndose al Colegio de Dentistas de Sevilla, inaugurado el 26 de marzo de aquel año.

24 A la exposición de la Historia de la Odontología, a nivel mundial, incluyendo también noticias españolas, dedica las cinco páginas precedentes.

25 Cfr. Landa Llona, S., y Vitoria ORTIZ, M. (1988), «Don Juan de Otaola, pionero de la odontología vizcaína», Revista Española de Estomatología, 3, 211-216.

26 (1924), Anuario Dental, 262-283; 1925, 41-70; 1926,, 61-108. Esta revista incluye también en el número de 1926 una semblanza del mismo autor titulada: «D. Cayetano Triviño Portillo y el cincuentenario de la creación del título de Cirujano-Dentísta», 168-176.

27 Ruiz Esquíu, E. (1923), «Evolución de la enseñanza de la Odontología en España», España odontológica, 3, 105-109; (1951), «Aclaraciones bibliográficas a la obra del Bachiller Francisco Martínez», Boletín del Consejo General de Colegios de Odontólogos y Estomatólogos, 116, 27-28; (1951), «Prioridad de la obra del Bachiller Francisco Martínez en el orden cronológico mundial de la odontología», Boletín del Consejo General de Colegios de Odontólogos y Estomatólogos, 118, 109-111.
} 
logía desde el año 1900 hasta nuestros días, presentada, y premiada, en el XIV Congreso Nacional de Odontología y I después de Aguilar (Madrid, 1945) siendo incluida en el libro de $\operatorname{actas}^{28}$ que se publicara dos años después. Con parecido rigor documental al del pionero Martínez Sánchez, la labor histórica de Ruiz Esquíu le hace merecedor de un profundo reconocimiento de los investigadores posteriores, sobre todo en su faceta puramente historiográfica.

A mediados de los cincuenta, en 1945 y en Barcelona, R. Arqués Miarnau edita su Historia anecdótica de la odontología a través del arte y de la literatura. Se trata de un libro de trescientas dos páginas en el que se recoge el pasado mundial de la dentistería haciendo hincapié, en cada capítulo, de lo referente a España.

Arqués ya deja claro en el prefacio del libro: «Como no existen documentos históricos de carácter profesional, constituirán los elementos básicos de nuestra obra los datos suministrados por papiros, manuscritos, libros, obras de arte, losas sepulcrales, objetos y utensilios encontrados en las tumbas antiguas y en excavaciones arqueológicas o accidentales» ${ }^{29}$, aunque en la bibliografía constan los textos de Riva Fortuño y Ruiz Esquíu por lo que debería haberse dedicado a la búsqueda de las referencias de este último para su estudio, echándose en falta, lamentablemente, los de Martínez Sánchez. El libro sigue un orden cronológico, en diez capítulos que van desde la prehistoria hasta la actualidad, ilustrado profusamente con fotografías, grabados y dibujos de gran interés ${ }^{30}$. Aunque la intención es buena y llega a convertirse en una crónica de mérito pues no existía en lengua castellana otro texto de similares características, las malas fuentes en las que bebió le conducen a errores perpetuados en datos concretos que no comprobó, lo cual resta valor a la obra.

Éste es el panorama a mediados de siglo. Ahora bien, la información obtenida no permite enjuiciar el periodo objeto de estudio si no se tienen en cuenta las siguientes circunstancias: En primer lugar, la falta de tradición de la profesión y su pobreza bibliográfica ${ }^{31}$ hizo que escaseara de forma notable el material a historiar. A ello puede añadirse el desinterés mostrado por quienes mejor pudieron haber aportado su colaboración, esto es, los historiadores de la medicina española, quienes no se dedicaron a esta rama médico-quirúrgica tan específica cuyos conocimientos no se explican, siquiera brevemente, durante la carrera de medicina, de ahí que no se tenga una

\footnotetext{
28 868-881.

29 ARQuÉS MiARnAU, R. (1945), Historia anecdótica de la odontología a través del arte y de la literatura, Barcelona, Salvat, p. 8.

30 En la portada queda constancia de su colaborador en estas cuestiones: Ramón Arqués y Navés.

31 Conviene recordar que hasta el año de 1799 son tan sólo ¡tres obras! puramente odontológicas las publicadas por españoles de nacimiento: Francisco Martínez de Castrillo, Coloquio breve y compendioso... (Valladolid, 1557); Francisco Antonio Peláez, Tratado de las enfermedades de la boca (Madrid, 1795) y Félix Pérez Arroyo, Tratado de las operaciones que deben realizarse en la dentadura (Madrid, 1799). Además, estas dos últimas no constituyen sino, en su conjunto, la traducción de la obra de Pierre Fauchard, Le Chirurgien Dentiste (París, 1728). De ahí que Martínez Sánchez se ve abocado a estudiar, prácticamente, lo publicado en su propio siglo.
} 
visión aproximada como ocurre con otras especialidades (obstetricia, pediatría, etc.) Por último, la no institucionalización de una asignatura -impensable- como la historia de la odontología, que tardaría tantísimos años en llegar, impidió su cultivo y fomento por previsibles discípulos tras cuyo aprendizaje sintieran atracción por el estudio de su pasado. Así las cosas, ¿cabía esperar otro resultado?

\section{HISTORIA ANECDÓTICA \\ DE LA ODONTOLOGÍA}

A TRAVES DEL, ARTE Y DE IA IITERATURA

inn 1.

DOCTOR R. ARQUES MIARNAU

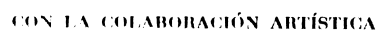

w):

BaMÓN ARQQUÉS Y NAVÉS

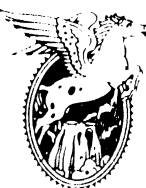

SAINAT EITTORES, S. A.

BARCELONA - BUENOS AIRES

194.5

La «Historia anecdótica de la Odontología» de Arques y Navés. 


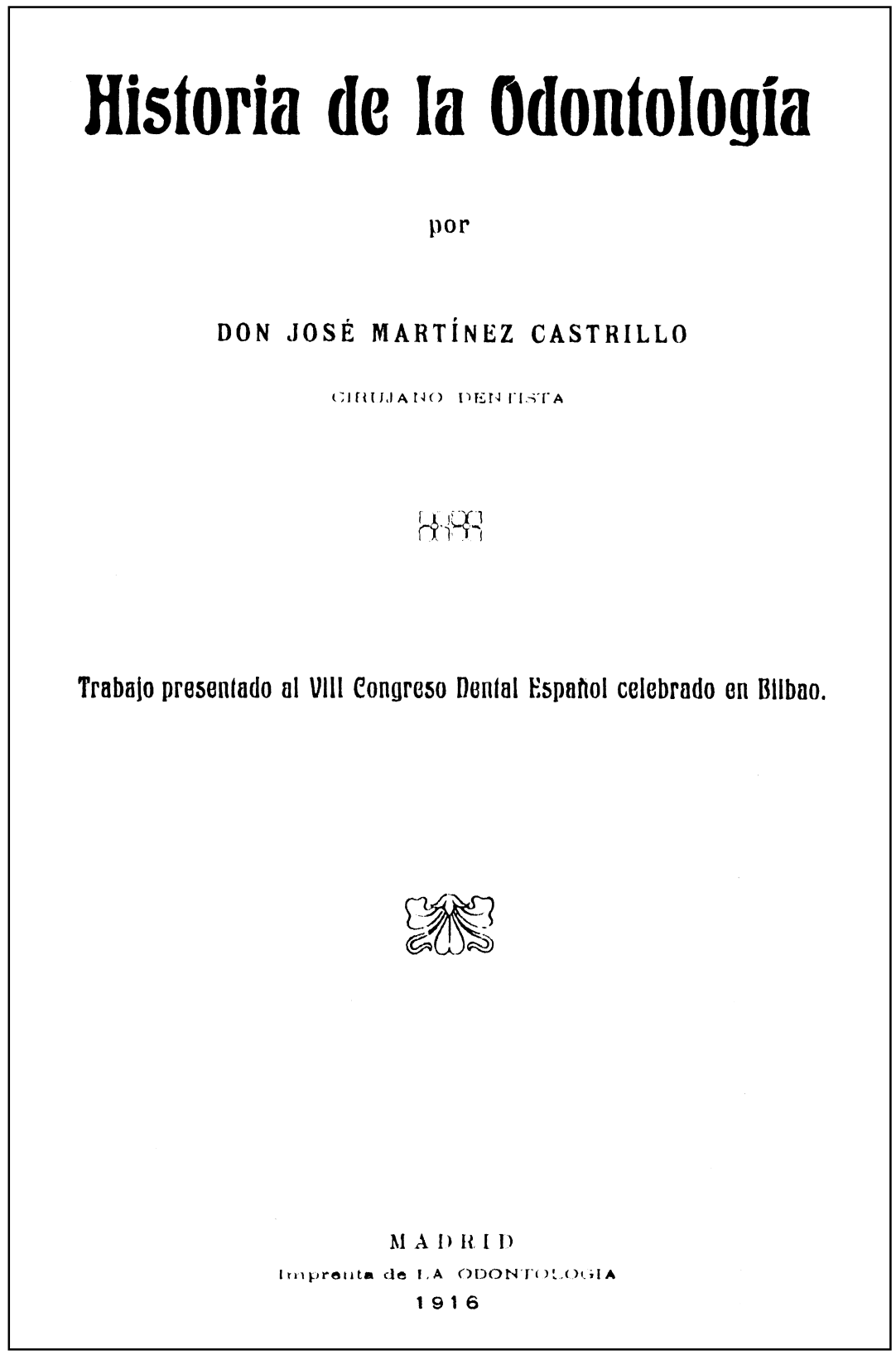

«Historia de la Odontología» de Martínez Castrillo. 


\section{Tratado de 0dontología}

POR

\section{Ramón Pons y 0ms}

CIRUJANO-DENTISTA

Expresidente del Circulo Odontoldgico

de Cataluna. Secretario del Congreso Odontoldgico

Esoanol de 1809 . Jundador de la Federación Odontoligica tispancle.

Laureado varias urees por al Cilresulo Odentoldgico y por Cingreses Odonto.

Iogicos. Soxio corresponsal de la Sexiedad Odomtológica Malacitana. Cofunda.

dor de La Moderna Estomatologia, redactor de La Odontologia,

Presidente de la Comision de Terminologla en el VII Congreso

Odontoldgico Espanot, Medalla de Oro en esta ulttima Asam.

Dea, socio fundador y corresponsal de la Asociacion

Espanola de Odontologia, elc.. etc.

(Tercera Edición)

TOMO PRIMERO

MADRID

Impronta de LA ODONTOLOCIA

1028

El «Tratado de Odontología» de Ramón Pons y Oms. 
CINCUENTA AÑOS DE HISTORIOGRAFÍA ODONTOLÓGICA ESPAÑOLA (1895-1945)

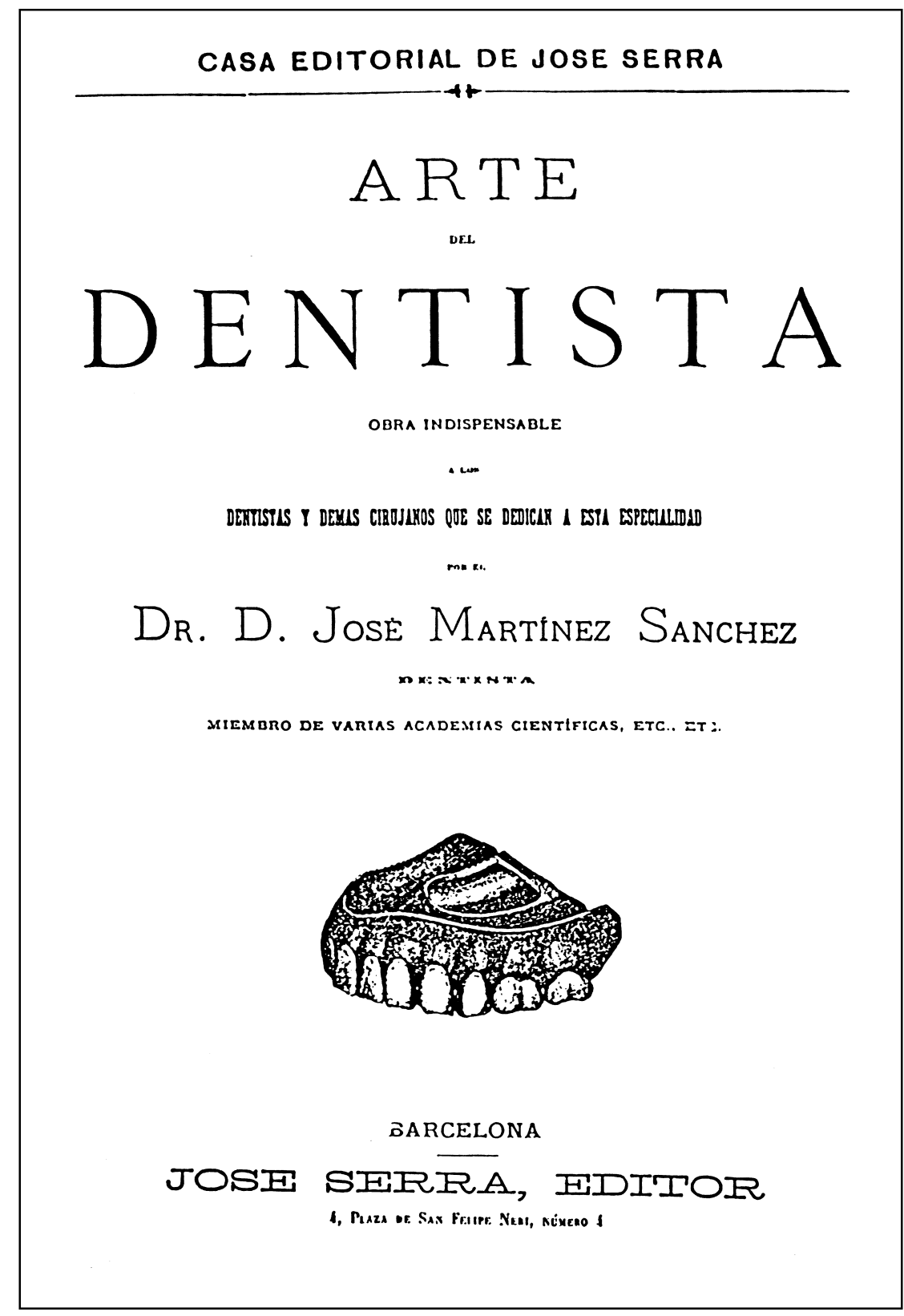

«Arte del dentista» de José Martínez Sánchez. 